\title{
Behavioral-Cognitive Inhibition Theory: Conceptualization of Posttraumatic Stress Disorder and Other Psychopathology Disorders
}

\author{
Nenad Paunović \\ Center for Andrology and Sexual Medicine, Karolinska University Hospital, Stockholm, Sweden. \\ Email: kontakt@kbterapi.se \\ Received September $9^{\text {th }}, 2010$; revised October $5^{\text {th }}, 2010$; accepted October $11^{\text {th }}, 2010$.
}

\begin{abstract}
A comprehensive and behaviorally formulated theory for psychopathology disorders termed as behavioral-cognitive inhibition theory is presented. It constitutes an integration and re-formulation of several influential psychological theories of psychopathology and empirical findings in imagery research. According to the behavioral-cognitive inhibition theory the development of PTSD and other psychopathology disorders are due to the development of dysfunctional respondent-functional-appraisal memories. The maintenance of psychopathology disorders is due to a continuous retrieval of dysfunctional respondent-functional-appraisal memories, to inhibittion of incompatible respondent-functional-appraisal memories, and to current dysfunctional appraisals and behaviors. Dysfunctional and incompatible respondent-functional-appraisal memories consist of respondent, discriminative, behavioral response, appraisal and consequence memory elements. It is proposed that the recovery from PTSD and other psychopathology disorders is accomplished when (a) strong enough matching incompatible respondent-functional-appraisal memories are retrieved in the same circumstances as dysfunctional respondent-functional-appraisal memories, (b) dysfunctional respondent-functional-appraisal memories become inhibited by incompatible respondent-functional-appraisal memories, and (c) new incompatible or functional contingencies are encoded, stored and become effective incompatible respondent-functional-appraisal memories. Concrete examples of respondent-functional-appraisal memory elements in emotional and personality disorders are presented. In addition, incompatible respondent-functional-appraisal memory elements are presented. Furthermore, central hypotheses of the behavioral-cognitive inhibition theory are formulated and important issues are discussed.
\end{abstract}

Keywords: Behavioral-Cognitive Inhibition Theory, Comorbidity, Respondent, Functional, Appraisal, Memories, Posttraumatic Stress Disorder, Emotional and Personality Disorders

\section{Introduction}

There are several influential theories for PTSD that have influenced the development of effective treatments for PTSD (e.g., Brewin, Dalgleish, \& Joseph, 1996; Ehlers \& Clark, 2000; Foa et al., 1986; Foa et al., 1989, Keane et al., 1995). However, no theory has provided a comprehensive behaviorally formulated conceptualization of PTSD and comorbid emotional and personality disorders. It is proposed that the behavioral-cognitive inhibition theory may be able to do so. The idea of multiple respondent-functional-appraisal memories conceptualized as a network that is used to explain comorbidity comes from multiple representational theories (Brewin et al., 1996; Power \& Dalgleish, 1997). Multiple psychopathology-related respondentfunctional-appraisal memories are conceptualized on the basis of identical terminology and theoretical mechanisms which solves (a) the interaction between multiple components problem (Dalgleish, 2004), and (b) the overdetermination problem that occurs when identical symptoms are explained by two different theories within one overarching model (e.g., when re-experiencing symptoms are due to activated fear structures and schema conflicts, Foa \& Rothbaum, 1998).

In addition to comorbidity, it is proposed that the behavioralcognitive inhibition theory improves upon influential PTSD theories and other psychopathology-specific CBT theories on other important issues. The behavioral-cognitive inhibition theory improves upon the emotional processing theory in several ways. First, the components are formulated in behavioral terms. This is in contrast to the hypothetical schema concepts (Foa \& Rothbaum, 1998). Second, the conceptualization of "incorporation of corrective/new information" as a therapeutic goal is not in itself an optimal formulation. It is important to broaden such a conceptualization by also including the incorporation of the following memory elements: respondent, discriminative, functional and consequence memory elements. Third, the numbing symptoms are more comprehensively explained (e.g., Follette \& Naugle, 2006; Litz, Orsillo, Kaloupek, $\&$ Weathers, 2000). According to Taylor (2006) numbing symptoms are suboptimally explained by influential PTSD theories. Fourth, the behavioral-cognitive inhibition theory separates between primary and secondary respondent-functional-appraisal memories that aids in the selection of treatment priorities.

The behavioral-cognitive inhibition theory behaviorally formulates vital components of the cognitive theory for PTSD developed by Ehlers and Clark (2000). Peri-traumatic appraisals are conceptualized as trauma-related primary appraisal memories, disjointed fragmentary memories as respondent and/or 
discriminative trauma-related memories, and "hotspots" as primary respondent memories. Peri-traumatic appraisals may include correct appraisal memories of threat or any other aspect that occurred during a traumatic event or faulty appraisal memories encoded and stored during and/or after the event. Trauma-related primary behavioral response memories of being e.g. passive or assertive during the trauma (behaviorally and/or cognitively) may influence current behaviors. Consequence memories of what happened immediately after the trauma may be correct or incorrect. It is important to correct faulty primary memories, to learn to discriminate between correct primary memories and current contingencies and to drop safety and avoidance behaviors in current contingencies that hinder the development of functional discriminations and appraisals. Such a behaviorally formulated conceptualization may be relevant to other emotional and personality disorders in addition to PTSD.

The behavioral-cognitive inhibition theory provides a comprehensive behaviorally formulated conceptualization of PTSD and/or other psychopathology symptoms as a result of both type 1 and type 2 traumatic events (Terr, 1991). Type 1 traumatic events include unanticipated single traumatic events. Type 2 traumatic events consist of long-standing or repeated exposure to traumatic events. The behavioral-cognitive inhibition theory may be able to explain dissociative symptoms and traumatic amnesia more often seen in victims of type 2 traumatic events (Terr, 1991), and more extreme flashbacks. Type 2 traumatic events may be encoded and stored as extremely dysfunctional respondent-functional-appraisal memories that include (a) extreme dissociative response and avoidance behavior memories leading to an automatic shutdown when such a memory is retrieved, and (b) extreme respondent memories that result in severe flashbacks when retrieved. Furthermore, the behavioral-cognitive inhibition theory may provide a plausible conceptualization of PTSD-related psychological disturbances seen in particularly vulnerable PTSD populations such as individuals with PTSD and comorbid substance abuse (Najavits, 2001), adult child sexual and physical abuse survivors (Cloitre, Cohen, \& Koenen, 2006), personality disorders (Young, Klosko, \& Weishaar, 2003), various types of vulnerable PTSD client populations (Mueser, Rosenberg, \& Rosenberg, 2009), and traumatized children (e.g. Cohen, Deblinger, \& Mannarino, 2006; Smith, Perrin, Yule, \& Clark, 2009). Examples of disturbances may include, but are not limited to, poor emotion regulation, excessively dysfunctional interpersonal cognitions and arrested cognitive and social development.

In addition to traumatic events, it ought to be possible to use typologies in order to describe variations of other types of distressing life events, for example distressing social experiences. A hypothetical example is described next. Type 1 distressing social events may include occasional or few social events that are quite distressing (e.g. experiencing occasional social harshness, criticism etc.). Type 2 distressing social events may encompass extremely distressing social events that have occurred repeatedly and/or for a long duration. One type of such event may be repeated bullying in school that many children may have experienced. Such experiences have been found in the majority of sexual offenders at the author's work place at the Karolinska university hospital in Stockholm specialized in the treatment of sexual disorders.

Other types of events that may be categorized according to typologies in order to illustrate variations are those that are incompatible to distressing life events. For example, life events that are pleasurable, nurturing and that boost self-efficacy. A fine-grained analysis of the interaction between the current situation and personally meaningful encoded and stored respondent-functional-appraisal memories may be important in order to more fully understand the development and maintenance of psychopathology disorders.

The behavioral-cognitive inhibition theory is influenced by the learning theory (Baldwin \& Baldwin, 2001; Keane, Zimering, \& Cadell, 1985; Martin \& Pear, 2007), emotional processing theory (Foa \& Kozak, 1986; Foa \& Rothbaum, 1998; Foa, Steketee \& Rothbaum, 1989), cognitive theory (Beck, Emery \& Greenberg, 1985; Beck, Rush, Shaw, \& Emery, 1979; Clark, 1999; Ehlers \& Clark, 2000), schema theory of personality disorders (Young et al., 2003), imagery research in emotional disorders (Hackman \& Holmes, 2004; Holmes, Arntz, \& Smucker, 2007), multi-representational theories (Brewin et al., 1996; Power \& Dalgleish, 1997), retrieval competition theory (Brewin, 2006), behavioral-cognitive vulnerability models (Barlow, 2002), stress appraisal theory (Lazarus \& Folkman, 1984), reciprocal inhibition theory (Wolpe, 1995), conceptualizations of numbing symptoms in PTSD (Follette \& Naugle, 2006; Litz, 1992), and the prolonged exposure counterconditioning method (Paunovic, 1999; 2002; 2003).

Central hypotheses that can be deduced from the behavioralcognitive inhibition theory are the following. First, that respondent-functional-appraisal memories can be functional and dysfunctional. In PTSD and other psychopathology disorders such memories are excessively dysfunctional when their retrieval leads to/influences: (i) excessively distressing respondent responses, (ii) dysfunctional predictions and appraisals, (iii) dysfunctional behavioral responses, (iv) dysfunctional consequences such as the continuation of psychopathology symptoms and negative consequences at work, during leisure time and impoverished relationships, (v) a lack of/the inhibition of functional respondent-functional-appraisal memory elements. Second, dysfunctional respondent-functional-appraisal memories can be optimally inhibited by incompatible respondentfunctional-appraisal memories under the following conditions (a) when strong or compelling enough incompatible respondent-functional-appraisal memories are retrieved, (b) when incompatible current contingencies are encoded and stored, (c) when one or both of the first two conditions occur in the same circumstances as when psychopathology-related respondentfunctional-appraisal memories are retrieved, (d) when incompatible respondent-functional-appraisal memories match central characteristics of dysfunctional respondent-functional-appraisal memories, and (e) when all dysfunctional respondent-functional-appraisal memories have been retrieved and inhibited. Third, current behaviors and appraisals are influenced by original encoding and storing, subsequent instances of retrieval, and current contingencies. When dysfunctional respondent-functional-appraisal memories are retrieved they may elicit excessive negative emotions, aversive physiological reactions, faulty appraisals and predictions and dysfunctional behavioral impulses. This may motivate an initiation of dysfunctional responses such as avoidance, safety behaviors and/or escape that shuts down the dysfunctional respondent-functional-appraisal memories. Fourth, it is proposed that dysfunctional primary 
memories should be the prioritized treatment target when dysfunctional respondent-functional-appraisal memories are the result of type 1 traumas that has led to the development of circumscribed PTSD psychopathology or any other type of circumscribed psychopathology. When dysfunctional respondent-functional-appraisal memories are associated with a broad range of psychopathology symptoms as a result of type 2 traumas primary and secondary respondent-functional-appraisal memories as well as training in necessary skills may be essential. Fifth, there ought to be an interaction effect between degrees of distressing/functional life events a person has encoded and stored permanently in memory vs. the degree of successful behavioral coping and functional appraisals that may be achieved in response to such events and memories.

\section{Behavioral-Cognitive Inhibition Theory}

The behavioral-cognitive inhibition theory consists of two main parts. First, it proposes that there exists dysfunctional vs. functional respondent-functional-appraisal memories that influence each other bi-directionally, and that current symptoms, appraisals and behaviors vs. respondent-functional-appraisal memories influence each other bi-directionally (see Figure 1). Second, current contingencies consist of retrieval triggers of respondent-functional-appraisal memories, current behaviors, appraisals and consequences. Such contingencies influence respondent-functional-appraisal memories both directly and indirectly through the encoding and storing of current contingencies that may develop into respondent-functional-appraisal memory elements.

Dysfunctional RFAM
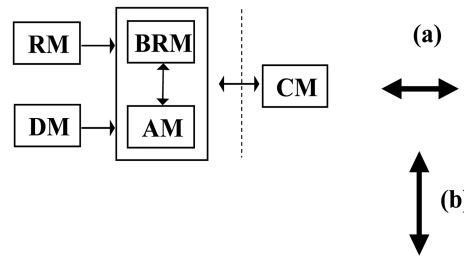

Current respondent-functional-appraisal contingencies

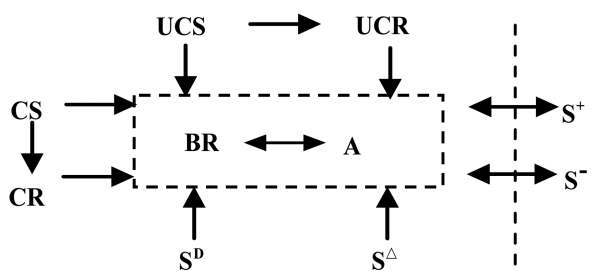

Note. Upper figures: $\mathrm{RM}=$ respondent memories, $\mathrm{DM}=$ discriminative memories, $\mathrm{BRM}=$ behavioral response memories, $\mathrm{AM}=$ appraisal memories, $\mathrm{CM}=$ consequence memories. Lower figure: $\mathrm{UCS}=$ unconditioned stimulus; $\mathrm{UCR}=$ unconditioned response; $\mathrm{CS}=$ conditioned stimulus; $\mathrm{CR}=$ conditioned response; $\mathrm{S}^{\mathrm{D}}=$ discriminative ess-dee stimulus; $\mathrm{S}^{\Delta}=$ discriminative ess-delta stimulus; $\mathrm{BR}=$ behavioral response, $\mathrm{A}=$ appraisal, $\mathrm{S}^{+}=$reinforcement; $\mathrm{S}^{-}=$punishment.

Figure 1.

Illustration of (a) the interaction between dysfunctional vs. incompatible respondent-functional-appraisal memories (RFAMs; see figures above), and (b) the interaction between RFAMs vs. current respondent-functional-appraisal contingencies.

\section{Respondent-Functional-Appraisal Memories}

It is proposed that respondent-functional-appraisal memories can exert an influence on current symptoms, behaviors and appraisals. Also, respondent-functional-appraisal memories can be incompatible or functional vs. dysfunctional. Each respondent-functional-appraisal memory consists of the following elements: respondent, discriminative, appraisal, behavior and consequence memory elements. Respondent-functional-appraisal memory elements can be primary or secondary. The behavioral-cognitive inhibition theory on a single respondentfunctional-appraisal memory level is presented in Figure 1.

\section{Respondent Memories}

Primary respondent memories consist of primary respondent stimuli and primary respondent response memories. Dysfunctional primary respondent memories in PTSD and other psychopathology disorders are illustrated in table 1 and 2. Dysfunctional primary respondent memories are acquired as follows. During or in proximity to excessively negative life events (unconditioned stimulus $=$ UCS) individuals react with excessive negative emotions, physiological responses and/or bodily pain reactions (unconditioned responses $=$ UCR). Both UCS and UCR are encoded by the individual's sensory apparatus and stored as primary respondent stimuli memories and primary respondent response memories respectively. In people who inherit a biological predisposition to react very strongly emotionally to negative environmental changes (Barlow, 2002) primary respondent stimuli memories are more likely to become associated with excessively distressing primary respondent response memories.

In PTSD primary respondent stimuli memories consist of central memories of the traumatic event (e.g., violent acts committed by a perpetrator or a violent motor vehicle crash). Primary respondent response memories include excessive unconditioned emotional responses of fear, horror, helplessness, physiological responses and bodily pain. The retrieval of dysfunctional primary respondent memories of a traumatic event is manifested as (a) vivid trauma-related intrusions of the gist of the trauma (i.e., visual images, sounds, actions, smells, etc.), and (b) excessively strong negative emotions, physiological responses and bodily pain that are identical or very similar to those experienced during the gist of the trauma.

Dysfunctional secondary respondent memories consist of (a) encoded and stored peripheral respondent stimuli and responses that occurred during and/or in close proximity to primary negative events, and (b) encoded and stored post-event stimuli and responses that have become associated with dysfunctional primary respondent memories during the retrieval of the latter. Secondary respondent memories may through their associations with primary respondent memories start to function as retrieval triggers of the latter. Secondary respondent memories associated with post-event respondent stimuli and responses are acquired when neutral stimuli become encoded and stored during the retrieval of primary respondent memories. Previously neutral post-event stimuli acquire a function as retrieval triggers of primary respondent memories. The development of an increasing number of various types of secondary respondent memories makes it increasingly difficult to avoid retrieval triggers and the retrieval of primary respondent memories. 
Incompatible primary respondent memories are acquired by the same mechanisms as dysfunctional primary respondent memories (e.g., Paunovic, 1999, 2002, 2003). When life events (UCS) elicit pleasurable or functional UCR (e.g. pleasurable emotions of happiness, joy, competence etc.), these UCS and UCR become encoded and stored as incompatible primary respondent stimuli and primary respondent response memories. Incompatible secondary respondent memories are acquired during (a) the encoding and storing of peripheral stimuli and responses during and/or in close proximity to primary incompatible/pleasurable events, and (b) the encoding and storing of post-event neutral stimuli that become associated with retrieved incompatible primary respondent memories. Such secondary respondent memories acquire the function of retrieval triggers of incompatible primary respondent memories. An increasing number of neutral stimuli may acquire such retrieval properties.

When current contingencies and retrieved dysfunctional primary respondent memories don't match each other they should be discriminated from each other. On the other hand, in potentially or realistically harmful situations dysfunctional primary respondent memories may have a protective and/or preparatory function that signal what may going to happen.

Stimuli and responses may be encoded through three learning pathways: direct experience, observational learning and/or information/instruction (e.g., Rachman, 1976, 1977). Storing (processing) may occur from (a) other people's viewpoint (Hackmann, Surawy, \& Clark, 1998), (b) an observation perspective (e.g., peritraumatic dissociation), or (c) an individual's own viewpoint (e.g. a traumatic event). The encoding may occur through various sensory channels and become stored accordingly. The most common memory quality in PTSD is visual memories of the trauma (Ehlers, Hackman, Steil, Clohessy, Wenninger, \& Winter, 2002). Incompatible stimuli and responses may also be encoded through three different pathways and various sensory channels, and stored from different viewpoints.

\section{Discriminative Memories}

Discriminative memories have predictive functions. When discriminative memories are retrieved in current contingencies predictions are made about the consequences of various courses of actions and/or about what will happen in a given situation.

Dysfunctional primary discriminative memories consist of encoded and stored peripheral stimuli and responses that occurred in close proximity to negative life events that were involved in the development of psychopathology symptoms. The retrieval of dysfunctional primary discriminative memories in innocuous current contingencies may lead to faulty predictions since they don't match the current situation. The retrieval of primary discriminative memories is manifested by intrusions of peripheral trauma-related memories (pre- and post-event). The retrieval of PTSD-related primary discriminative memories serves a function of faulty warning signals of serious threat (Ehlers et al., 2002). It is proposed that the same mechanism exists in other psychopathology disorders with psychopathology-specific erroneous predictive functions (see Table 1 and 2).

Dysfunctional secondary discriminative memories consist of encoded and stored neutral stimuli that have become associated with retrieved primary discriminative memories. Retrieved secondary discriminative memories may function as retrieval triggers of primary discriminative memories and may acquire similar predictive functions as the latter. The development of an excessive number of various types of dysfunctional secondary discriminative memories may lead to excessive amounts of faulty predictions in various types of innocuous situations.

Functional primary and secondary discriminative memories include correct predictions in line with what will most probably happen in current contingencies, including if various courses of actions are taken. Functional primary and secondary discriminative memories are developed as a result of increasingly correct discrimination learning experiences of the predictive functions that various types of stimuli and responses have. Functional discrimination learning is dependent upon taking courses of actions in innocuous situations that challenges dysfunctional and incorrect predictions. Corrective experiences that disconfirm faulty predictions when dysfunctional primary and seconddary discriminative memories are retrieved will be encoded and stored as functional discriminative memories. If such functional discriminative memories become compelling or strong enough they acquire the capacity to inhibit dysfunctional discriminative memories. When functional primary and secondary discriminative memories are retrieved they will instigate correct predicttions regarding what will happen in the retrieval situation and what consequences a given behavior will have. This increases the probability that the individual will engage in functional coping behaviors. The disconfirmation of predicted negative consequences during the retrieval of dysfunctional discriminative memories is not possible to acquire if dysfunctional behavioral responses are enacted. Such behavioral responses hinder corrective experiences from being acquired that may change the predictive stimulus functions of retrieval triggers. Correct predictions may in potentially dangerous or in other ways harmful situations signal that escape, avoidance or appropriate defensive behaviors are highly functional.

\section{Behavioral Response Memories}

There are three fundamental ways to cope with psychologically or physically potentially harmful situations or negative events: (a) avoidance, escape and safety behaviors, (b) attack or resistance, or (c) freezing which is an innate non-volitional response that is elicited when escape or aggression is not possible during an attack (e.g., Barlow, 2002, pp. 219-220, 283). Alternatively, the freezing response may be an unconditioned respondent response. Such behavioral responses are encoded and stored as primary behavioral response memories that may become dysfunctional if their retrieval instigates inappropriate responses in current contingencies. Dysfunctional primary behavioral response memories may function as predispositions to respond dysfunctionally when current contingencies retrieve such memories. The retrieval of dysfunctional primary behavioral response memories may increase the risk of responding similarly in current innocuous situations. This may lead to short-term relief due to a temporary shut-down of retrieved dysfunctional respondent-functional-appraisal memories.

Secondary dysfunctional behavioral response memories consist of encoded and stored dysfunctional coping behaviors that have been enacted during the retrieval of dysfunctional respondent-functional-appraisal memories in innocuous situations. Such dysfunctional behavioral coping may constitute psychopathology symptoms per see (e.g., avoidance in PTSD [APA, 1994]). The retrieval of dysfunctional secondary behavioral 


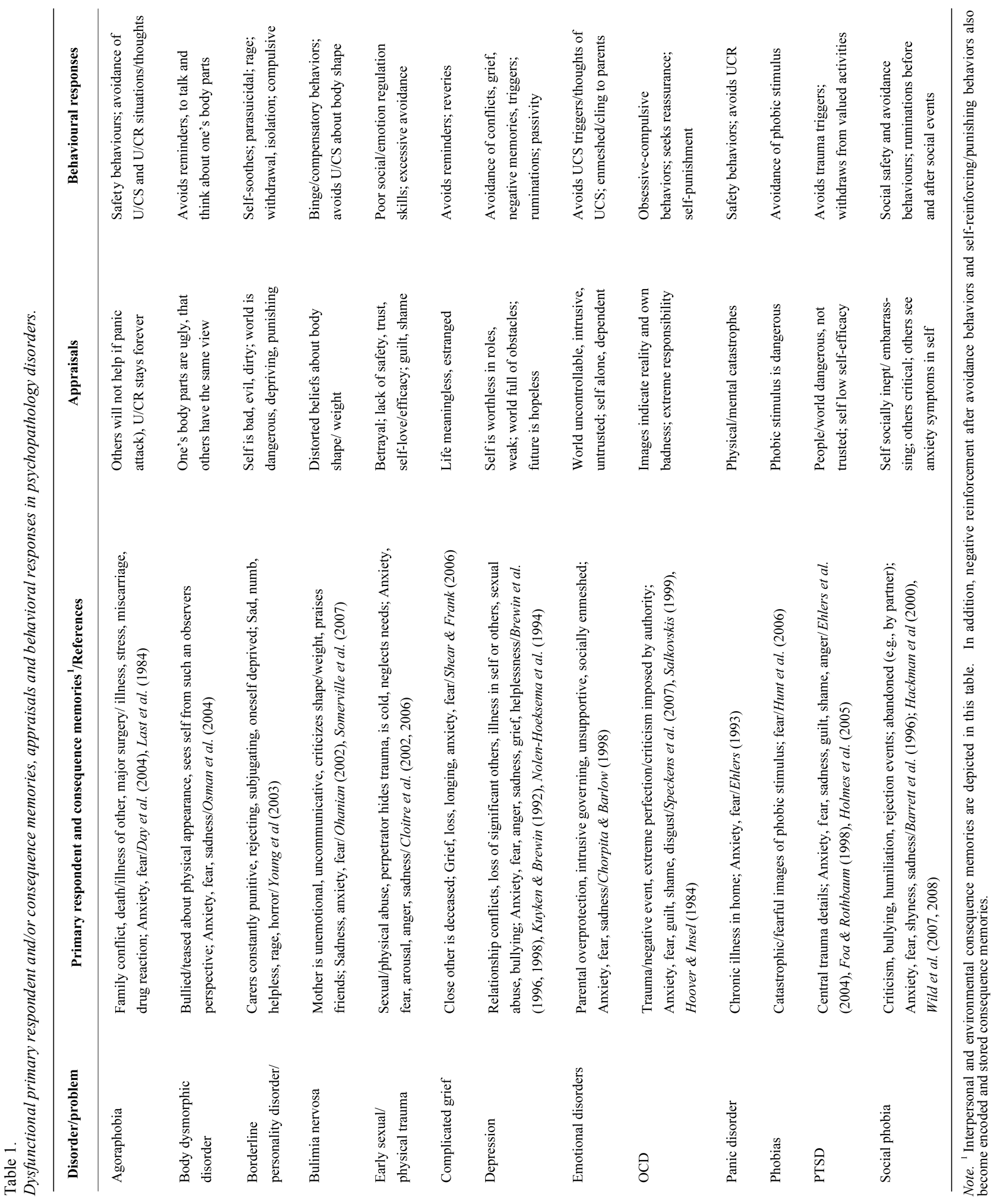




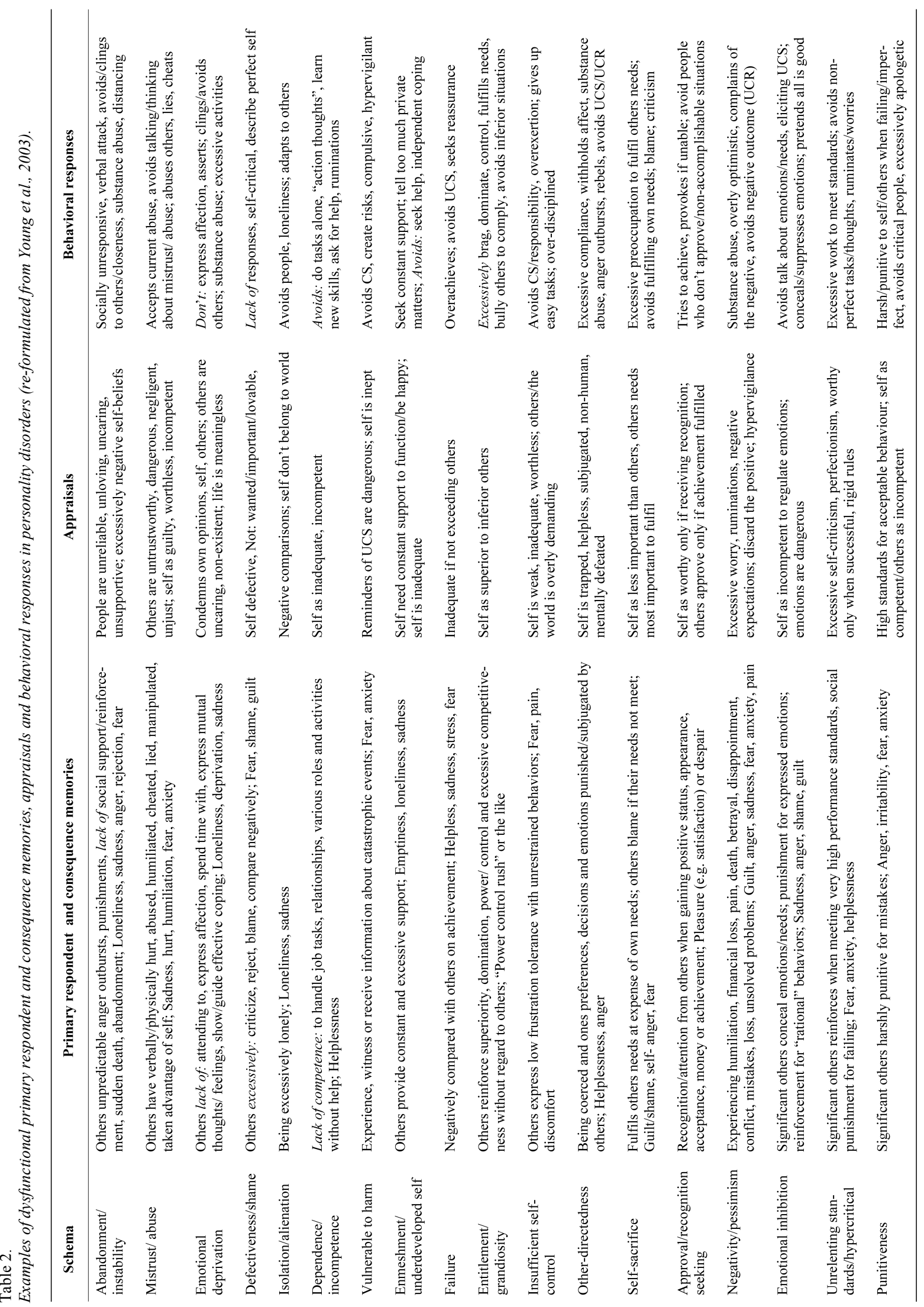


response memories increases the probability of engagement in dysfunctional behavioral coping when intrusions and other symptoms occur in innocuous situations. Behaviors such as avoidance, escape or attack are associated with faulty predictive functions. This includes the faulty prediction that negative consequences will be neutralized or minimized if such behaviors are pursued.

Some emotional behaviors have a communicative function (Barlow, 2002) that can be concealed. Individuals with PTSD deliberately conceal or withhold emotional expression (Roemer, Litz, Orsillo, \& Wagner, 2001). This withholds the necessary emotional communication that is needed in order to receive social support from others. The absence of social support may be encoded and stored without an awareness that this is due to the emotional concealment behavior. Alienation and emotional distancing from others may in part be related to the retrieval of such behavioral response (emotional concealment) and consequence memories (lack of social support). Functional behaviors such as telling about the trauma to others may lead to social support. However, distress in significant others, beliefs that it is harmful to talk about distressing events, and dysfunctional responses such as avoidance and escape by significant others may lead to an absence of or inadequate social support.

Incompatible behavioral response memories may be acquired during distressing, neutral and/or positive situations. Memories of successful coping behaviors in distressing situations or participation in appreciated activities promote successful coping and participatory enjoyment in future similar situations. If communicating negative events and emotions to others leads to social support both the behavior, emotions, stimuli in the situation and related appraisals become encoded and stored as incompatible respondent-functional-appraisal memories. Engagement in appreciated activities may include activities related to valued relationships, activities, goals etc. The retrieval of such behavioral response memories may lead to an increased probability that similar behaviors will be enacted in current circumstances.

Cognitive behavioral responses have identical functions as their overt behavioral counterparts. Dysfunctional cognitive primary behavioral response memories consist of encoded and stored dysfunctional cognitive behavioral responses. These may include peritraumatic dissociation, perceptual avoidance, distraction and obsessive cognitive behaviors. Peritraumatic dissociation (Ozer \& Weiss, 2004) may have a protective function against overwhelming emotions during a traumatic event. During post-event retrieval of peritraumatic dissociation memories numbing responses may ensue. Perceptual avoidance is a survival mechanism that has been found in adult survivors of child sexual and physical abuse with complex PTSD (Kohlenberg, Tsai, \& Kohlenberg, 2006). Its function seems to be an avoidance of encoding retrieval triggers of the abuse, the abuser and associated emotions, particularly if physical escape may not be possible. Otherwise the effects of the trauma would be more intrusive and preclude any caretaking. Downsides includes a compromised ability to identify, experience and describe emotions. Distraction consists of a purposeful attentional focus away from distressing stimuli and responses. Obsessive cognitive behaviors are excessively repetitive cognitive responses whose function is to decrease distressing events, images or impulses.
Secondary dysfunctional cognitive responses include distraction, effortful suppression, obsessions, ruminations, worries, cognitive safety behaviors, dissociation and trying not to think about negative memories or events (e.g. Barlow, 2002; Ehlers \& Clark, 2000; Foa \& Kozak, 1986; Kubany \& Ralston, 2006; Watkins, 2008). These cognitive responses are encoded and stored as secondary cognitive behavioral response memories. When dysfunctional cognitive behavioral response memories are retrieved they may (a) block the retrieval of other dysfunctional respondent-functional-appraisal memories, and (b) motivate similar responses to current distressing stimuli and emotional responses.

Incompatible primary cognitive behavioral responses may be encoded during primary distressing, neutral or positive events/ situations and stored as incompatible primary cognitive behavioral response memories. An individual may cope cognitively successfully in distressing situations. Cognitive mastery responses may consist of an ability to nurture/calm oneself, elicit positive emotions or functional physiological states, approach situations imaginally while maintaining a sense of control etc. Mental planning is defined as thinking about or planning in one's mind about what one might be able to do to minimize physical or psychological harm, to make the experience more tolerable, or to influence the response of an assailant during a traumatic event (Ehlers, Clark, Dunmore, Jaycox, Meadows, \& Foa, 1998).

Incompatible secondary cognitive behavioral responses are encoded and stored during the retrieval of primary respondentfunctional-appraisal memories. There are at least three types of secondary incompatible or functional cognitive behavioral responses that can be enacted. First, cognitive approach behaviors during the retrieval of distressing respondent-functional-appraisal memories such as in imaginal exposure to a traumatic event (Foa \& Rothbaum, 1998). Second, effortful retrieval of incompatible respondent-functional-appraisal memories of e.g. valued events with significant others, appreciated activities, competency situations etc (e.g., Paunovic, 1999; 2002; 2003). Third, imagery rescripting of dysfunctional respondent-functional-appraisal memories by imaginally changing negative courses of events into mastery and nurturing experiences (e.g., Holmes et al., 2007).

A lack of incompatible behavioral response memories may be due to skills deficits. Important skills include social, motoric and intellectual skills. Skills deficits may likely lead to failed coping attempts that become encoded and stored as dysfunctional behavioral response memories. If relevant skills are developed it increases the probability of successful coping and adaptive behaviors in appropriate situations. Such successful coping is encoded and stored as an incompatible behavioral response memory. The retrieval of such memories constitutes indications that one has the capability to successfully cope with the relevant situations.

\section{Appraisal Memories}

Dysfunctional primary appraisal memories are acquired as follows. During primary negative events, innate and automatic appraisals may be elicited and/or conscious appraisals deliberately enacted. These appraisals are encoded and stored as primary appraisal memories. In PTSD primary appraisals include, 
but are not limited to, serious life threat or threat of harm and/or helplessness. If distressing emotions are not correctly associated with the eliciting negative life event within the next few hours, the individual may be unable to specify an antecedent to the distressing emotions (Barlow, 2002). In addition, an individual may incorrectly appraise the situation in a dysfunctional way. As a result, dysfunctional primary appraisal memories may develop that contains faulty appraisals not associated with the eliciting events and/or incorrect appraisals of the situation. During the post-event sequel, retrieved primary appraisal memories may be incorrectly attributed to current contingencies rather than to the nature of retrieval triggers and dysfunctional respondent-functional-appraisal memories.

Dysfunctional secondary appraisal memories may develop during the retrieval of primary respondent-functional-appraisal memories. Retrieval triggers may be incorrectly appraised during intense negative emotions. Such appraisals are encoded and stored as dysfunctional secondary appraisal memories. In PTSD negative appraisals in the trauma aftermath predict the maintenance of PTSD (e.g., Ehlers, Mayou, \& Bryant, 1998; Engelhard, van den Hout, Arntz, \& NcNally, 2002). The content of PTSD-related appraisal memories include catastrophic and dysfunctional appraisals of trauma intrusions and trauma triggers as extremely dangerous, that PTSD symptoms are indications of self and the future in negative ways, and that other people's behaviors are indications that they are not trustworthy and understanding (Ehlers \& Clark, 2000; Foa \& Rothbaum, 1998).

Dysfunctional appraisal memories are logically associated with other respondent-functional-appraisal memory elements. In addition, repetitive appraisals associated with e.g. guilt, anger or shame may become habitually conditioned with images or thoughts of the trauma (i.e., primary respondent memories). Such appraisals may repeatedly recondition the traumatic memory or other dysfunctional respondent-functional-appraisal memory elements through higher-order language conditioning (e.g., Kubany \& Manke, 1995). Conversely, if respondent memories or other respondent-functional-appraisal memory elements are reevaluated (e.g., Davey, 1992), the dysfunctional language and primary conditioning may be given an opportunity to become inhibited.

Incompatible primary appraisal memories may be developed during successful coping in response to primary negative events or during participatory enjoyment in primary meaningful or "positive" events. Incompatible secondary appraisal memories are acquired during the retrieval of primary respondent-functional-appraisal memories. Stimuli and responses that are encoded and appraised during the retrieval of primary respondentfunctional-appraisal memories become stored as secondary appraisal memories. The encoding and storing of coping selfefficacy appraisals includes appraisals of one's perceived capability to manage one's personal functioning and environmental demands during the aftermath of traumatic events (Benight \& Bandura, 2004) and other types of distressing situations. Other types of incompatible appraisal memories include appraisals of lovability (that one deserves affection and caring), appraisals of quality of life-ability (the ability to enjoy present situations, be close to others etc.) and appraisals of achievement (achieving important goals).

\section{Consequence Memories}

Dysfunctional primary consequence memories are encoded and stored dysfunctional consequences that occurred during primary events, behaviors and appraisals. Dysfunctional intrapersonal primary consequence memories consist of encoded and stored dysfunctional consequences of behaviors and appraisals enacted by the individual in primary events. Dysfunctional intrapersonal secondary consequence memories are encoded and stored dysfunctional consequences of behaviors and appraisals enacted by the individual during dysfunctional respondent-functional-appraisal memory retrieval. Examples include dysfunctional negative reinforcement, higher-order language conditioning of distressing emotions and intrusions and self-initiated positive reinforcement of dysfunctional behaviors.

Dysfunctional interpersonal primary consequence memories consist of encoded and stored dysfunctional responses of others to an individual's behaviors or appraisals (or lack thereof) during or in close proximity to primary events. Encoded and stored responses of others may include (a) reinforcements of dysfunctional behaviors and appraisals, (b) punishments (e.g. being harsh, critical and negligent) of functional behaviors and appraisals, (c) non-contingent punishments, and (d) a lack of help and support to the individual. The retrieval of dysfunctional interpersonal consequence memories may be related to the numbing symptoms alienation/distancing from others, less enjoyment in appreciated activities (e.g. socially-related activties), and diminished ability to feel positive emotions (particularly in relation to other people). Dysfunctional interpersonal secondary consequence memories consist of encoded and stored experiences of other people's dysfunctional responses to behaviors and appraisals enacted during dysfunctional respondent-functional-appraisal memory retrieval. Other people's responses may include (a) reinforcements for dysfunctional behaviors and appraisals (e.g., avoidance and faulty appraisals), and (b) punishments for incompatible/functional behaviors and realistic appraisals during dysfunctional respondent-functionalappraisal memory retrieval. Such learning increases the likelihood of dysfunctional coping and decreases the likelihood of engagement in functional behaviors and appraisals during dysfunctional respondent-functional-appraisal memory retrieval. For example, if talking about a trauma, crying and displaying tears or revealing negative thoughts and emotions leads to repeated negative reactions from others (Follette \& Naugle, 2006), such negative responses will be encoded and stored as dysfunctional interpersonal consequence memories. Such consequence memories may perpetuate PTSD and other psychopathology symptoms and inhibit incompatible respondent-functionalappraisal memories.

Incompatible primary consequence memories are developed during the encoding and storing of reinforcing or absence-ofpunishing consequences to incompatible/functional behaviors and appraisals during or in close proximity to primary events. Incompatible intrapersonal primary consequence memories include memories of self-enacted consequences whereas incompatible interpersonal primary consequence memories consist of memories of consequences enacted by others. Incompatible secondary consequence memories constitute encoded and stored experiences of intrapersonal and interpersonal reinforcements or absence-of-punishing consequences during incompatible and/or dysfunctional respondent-functional-ap- 
praisal memory retrieval. The retrieval of incompatible consequence memories may increase the probability that the individual may engage in the reinforced or absence-of-punished behaviors.

\section{Current Contingencies}

Current behaviors and appraisals are influenced by currently retrieved respondent-functional-appraisal memory elements as well as current contingencies. Table 1 and 2 illustrate respondent and consequence memory elements that influence current behaviors and appraisals in emotional and personality disorders. It is hypothesized that currently enacted psychopathology-related appraisals and behaviors closely match retrieved psychopathology-related primary and secondary appraisal and behavioral memories.

\section{Retrieval Triggers}

Psychopathology-related retrieval triggers constitute encoded stimuli and responses in current contingencies that match characteristics of stored dysfunctional respondent-functional-appraisal memory elements. Both the degree of similarity between current encoding and stored respondent-functional-appraisal memory elements, and the quality of encoding and storing may determine the effectiveness of memory retrieval. Primary retrieval triggers closely match dysfunctional primary respondent-functional-appraisal memory elements. In chronic PTSD as a result of interpersonal violence a primary retrieval trigger would constitute the encoding of a person or behavior in a current situation that resembles a perpetrator on key physical characteristics or a violent behavior committed by a perpetrator. The encoding and storing of such primary retrieval triggers may through such a memory process start to function as a faulty secondary discriminative memory of danger. Such memory processes may through time more or less permanently modify the original memory of the event and the perpetrator since the encoded and stored retrieval triggers usually may have some new characteristics that are dissimilar to the original stimuli (Loftus, 2003). Secondary retrieval triggers match characteristics of secondary respondent functional-appraisal memory elements and may become encoded and stored as additional secondary respondent-functional-appraisal memory elements. Again, the respondent-functional-appraisal memory elements may become modified due to some dissimilarity between currently encoded and stored secondary retrieval triggers and existing primary/secondary respondent-functional-appraisal memory elements. Retrieved secondary respondent-functional-appraisal memory elements may effectively retrieve primary respondentfunctional-appraisal memories if there are strong associations between primary and secondary memory elements. Neutral stimuli and responses that are encoded during respondentfunctional-appraisal memory retrieval may become associated with the latter and start to function as secondary respondentfunctional- appraisal memory elements.

Incompatible primary retrieval triggers consist of encoded stimuli and responses in current contingencies that match incompatible primary respondent-functional-appraisal memory elements. Incompatible secondary retrieval triggers consist of currently encoded stimuli and responses that match incompatible secondary respondent-functional-appraisal memory ele- ments. It is hypothesized that the same principles that may apply for psychopathology-related primary and secondary retrieval triggers are also generalizable to incompatible primary and secondary retrieval triggers.

\section{Behavioral Strategies}

Primary behavioral and cognitive strategies are enacted in response to primary events. Coping strategies during negative events include being passive, avoid or escape the situation or trying to deal with/confront it (e.g., attack). Secondary behavioral and cognitive strategies occur in response to dysfunctional retrieval triggers and retrieved respondent-functional-appraisal memory elements. Avoiding/escaping innocuous retrieval triggers is dysfunctional whereas doing the same in response to potentially harmful situations is functional. During the retrieval of dysfunctional respondent-functional-appraisal memory elements dysfunctional behavioral strategies (overt and covert) may be utilized in order to inhibit the retrieved memory. Avoidance of retrieval triggers prevents a retrieval of dysfunctional respondent-functional-appraisal memories. Behavioral avoidance/escape may include excessive behavioral activation, compulsive behaviors, planning ahead of how to avoid triggers, escaping when confronted with triggers or during intrusions, the use of alcohol/substances and safety behaviors. Cognitive avoidance may include distraction, thought suppression, obsessive thinking, dissociation, actively trying not to think about distressing memories, rumination and worrying.

Exposure to innocuous situations and conversations about past negative events is objectively safe. The absence of negative consequences (e.g., decline in negative emotions, nonoccurrence of negative events) during functional coping (e.g., approaching innocuous stimuli) is encoded and stored as incompatible respondent-functional-appraisal memory elements and may gain a function as inhibitors to dysfunctional respondent-functional-appraisal memory elements. Behavioral and cognitive avoidance, escape and safety behaviors prevent the encoding of such incompatible experiences.

Behavioral activation in meaningful activities and behaviors (e.g., Martell, Addis, \& Jacobson, 2001) that elicit pleasurable emotions and functional consequences are all encoded and stored as incompatible respondent-functional-appraisal memory elements. The retrieval of such memory elements may be utilized as inhibitors to dysfunctional respondent-functional-appraisal memory elements. Functional behavioral activation and incompatible respondent-functional-appraisal memory retrieval should map onto relevant problem areas or themes to the dysfunctional respondent-functional-appraisal memory elements in order to function as effective inhibitors.

\section{Current Appraisals}

Current appraisals are influenced by (a) what is encoded and is occurring in current contingencies (e.g., present reinforcements and punishments), (b) presently retrieved respondentfunctional-appraisal memory elements, (c) current behavioral and cognitive coping/engagement, (d) consequences of the former, and (e) cognitive elaboration and storing of the former. Present encoding may be influenced by the nature of currently retrieved respondent-functional-appraisal memory elements. Faulty attributions of retrieved dysfunctional primary appraisal 
memories as due to currently encoded stimuli and responses is encoded and stored as dysfunctional secondary appraisal memories. It is important to discriminate between current retrieval triggers from retrieved dysfunctional respondent-function-alappraisal memory elements. Falsely predicting that current retrieval triggers of retrieved incompatible/functional respondent-functional-appraisal memories are indications that something similar is going to occur in the present situation will lead to non-fulfilled expectations. Lack of such discrimination skills may lead to disappointment or other negative responses.

Functional, incompatible or realistic appraisals may be developed or strengthened by (a) consciously encoding and storing aspects of current contingencies that are incompatible to dysfunctional respondent-functional-appraisal memories, (b) consciously retrieving incompatible respondent-functionalappraisal memories, and (c) engaging in functional behavioral/cognitive responses (e.g., approaching innocuous stimuli, engaging in meaningful activities, coping effectively with situations). Such behavioral engagements may contribute to the development of incompatible/functional respondent-functionalappraisal memories.

Current appraisals that are compatible with present realistic circumstances are termed as realistic appraisals. Current appraisals of correctly attributing symptoms to retrieved respondent-functional-appraisal memory elements that have been triggered by retrieval triggers may lead to a decrease in dysfunctional appraisals and increased functioning. New functional appraisals may be developed, encoded and stored as secondary appraisal memories that have the potential to inhibit dysfunctional respondent-functional-appraisal memories.

The retrieval of dysfunctional respondent-functional-appraisal memory elements may influence appraisals of current retrieval triggers and coping responses. Dysfunctional behavioral responses may be appraised as functional due to appraised short-term advantages. Learning the realistic short- and long- term implications of such coping responses may lead to the development of functional appraisals of engaging in such behaviors. The encoding and storing of functional appraisal memories may guide the enactment of functional behaviors.

\section{Reinforcement and Punishment}

Reinforcement and punishment constitute primarily intraand interpersonal stimuli and environmental events that function as consequences to behavioral responses and appraisals. Reinforcement and punishment can be conscious or non-deliberate. Functional vs. dysfunctional behaviors and appraisals can be reinforced or punished. For example, a child may subtly support a mother's avoidance behavior and a spouse "invaliddate" emotional disclosure (Follette \& Naugle, 2006). A critical, harsh and hostile environment is related to a poorer outcome in empirically supported treatments for PTSD (Tarrier, Sommerfield, \& Pilgrim, 1999). A social harshness respondent-functional-app-raisal memory may thus develop. Social support may function as reinforcement of functional or dysfunctional responses and appraisals. If the function of social support is to shut down the retrieval of dysfunctional respondent-functionalappraisal memories it may be dysfunctional since it prohibits the possibility of inhibiting dysfunctional respondent-functional-appraisal memories. Social support-seeking behaviors may be punished or reinforced. Punishments for social-support seeking behaviors may be due to discrimination deficits of from who to seek social support (Follette \& Naugle, 2006). Social support may be sought in order to suppress or avoid the retrieval of dysfunctional respondent-functional-appraisal memories (i.e., safety behaviors). Reinforcing and punishing stimuli are encoded and stored as reinforcing vs. punishing consequence memories.

\section{Discriminative Stimuli}

Discriminative stimuli consist of external or internal stimuli whose function is to signal (a) the consequences to responses and/or appraisals, and (b) what will happen next in specific situations. Stimuli that function as faulty discriminative stimuli for the occurrence of negative events (e.g., punishments) do so due to the retrieval of dysfunctional respondent-functionalappraisal memories. Realistic predictive functions of discriminative stimuli for negative occurrences increases the chances of functional coping since it may provide an increased possibility for preparation and prevention. The encoding of stimuli or responses that signal the occurrence of meaningful or pleasurable events due to respondent-functional-appraisal memory retrieval may constitute realistic or unrealistic predictions. Faulty predictions of pleasurable/meaningful events may lead to positive punishment (e.g., non-fulfilled positive predictions). Correct predictions of pleasurable/meaningful events lead to positive reinforcement. Discriminative stimuli, enacted behaviors (or a lack thereof) and its consequences are encoded and stored as respondent-functional-appraisal memory elements.

\section{PTSD Symptoms, Associated Features and Mechanisms}

Intrusions in chronic PTSD are conceptualized as follows. The encoding of current retrieval triggers leads to the retrieval of trauma-related respondent-functional-appraisal memories. Primary respondent-functional-appraisal memories of a traumatic event are hypothesized to generate the most distressing intrusions (flashbacks, severe nightmares, severe physiological, emotional and pain responses) and consist of the following encoded and stored elements (see also Figure 1):

- Central details of the event (primary respondent stimuli memories)

- Emotional, physiological and pain responses experienced during the gist of the trauma (primary respondent response memories)

- Appraisals during the gist of the trauma (primary appraisal memories)

- Behavioral responses enacted during the gist of the trauma (primary behavioral response memories)

- Consequences during and/or soon after the trauma (primary consequence memories)

The possibly more common intrusions in PTSD may constitute secondary respondent-functional-appraisal memories (e.g., Ehlers et al., 2002). These memories are associated with immediate pre-trauma situations and peripheral stimuli that were encoded in close proximity to or during the trauma. The retrieval of such memories function as faulty warning signals of threat. The continuous on-going threat experience in chronic PTSD is due to an on-going partial-full retrieval of trauma-related respondent- functional-appraisal memories. Re- 
trieved trauma-related respondent-functional-appraisal memories lead to/influence:

- Painful emotional, physiological and bodily respondent responses

- Spontaneous sensory-based intrusions of the trauma and peripheral stimuli

- Faulty current appraisals of (a) the dangerousness of presently encoded stimuli and responses, (b) other people as nontrustworthy, non-understanding, non-safe, (c) self as lacking in self-efficacy and other negative appraisals (e.g., crazy, irremediably wounded, non-functional), and (d) avoidance and escape from retrieval triggers as functional

- Dysfunctional avoidance of retrieval triggers that prevents the retrieval of trauma-related respondent-functional-appraisal memories

- Dysfunctional escape from trauma-related retrieval triggers or safety behaviors whose function is to shut down retrieved trauma-related respondent-functional-appraisal memories

- Inhibition of (a) incompatible currently encoded stimuli and responses, and (b) retrieved incompatible respondent-functional-appraisal memories.

The fragmentation of traumatic memories in PTSD may be explained by the initial retrieval and an immediate shutdown of excessively distressing respondent-functional-appraisal memories due to automated or conscious avoidance behaviors. Complementarily, it may be due to an automatic biological process that protects against overwhelming emotional and other types of pain.

Psychogenic amnesia may constitute a temporary inaccessibility or shutdown of trauma-related respondent-functionalappraisal memories. This may be a result of initially successful conscious avoidances of dysfunctional respondent-functionalappraisal memory retrieval that has become automatic, to encoded and stored peritraumatic dissociation, and or current dysfunctional coping that blocks the access to trauma-related respondent-functional-appraisal memory elements.

The "here and now" quality of intrusions may be explained by the retrieval of primary respondent memories (e.g., flashbacks). When primary respondent memories are retrieved the currently encoded stimuli and responses may be appraised as a current threat and be preferentially attended to (i.e., attentional bias).

Numbing symptoms in chronic PTSD may be conceptualized as: (a) dysfunctional behavioral response memories of restricted emotional expression in interpersonal situations (Miller \& Litz, 2004; Roemer et al., 2001), (b) a lack of reinforcing activities as proposed in behavioral theories of depression (e.g., Lewinsohn, Hoberman, Teri, \& Hautzinger, 1985) that is the long-term consequence of the avoidance of retrieval triggers, (c) inhibition of incompatible memories by trauma intrusions (Amdur, Larsen, \& Liberzon, 2000; Litz et al., 2000; Miller \& Litz, 2004; Spahic-Mihajlovic, Crayton, \& Neafsey, 2005), and (d) dysfunctional consequence memories of social punishment for expressing negative emotions or the trauma (Follette \& Naugle, 2006).

Hyperarousal symptoms are due to a continuous partial retrieval of trauma-related respondent-functional-appraisal memories that emotionally drains the individual of cognitive resources and leads to a heightened physiological baseline (e.g., Foa, Riggs, \& Gershuny, 1995).
Dysfunctional pretrauma, trauma and posttrauma respondentfunctional-appraisal memories may retrieve and potentiate each other in each direction and lead to comorbid psychopathology symptoms (see Table 1 and 2). Dysfunctional respondent-functional-appraisal memories that developed in early life may become more or less strongly interconnected with dysfunctional respondent-functional-appraisal memories formed in adolescence and/or adulthood and generate PTSD symptoms and comorbid psychopathology.

Peritraumatic dissociation may be conceptualized as an automatic cognitive distancing response during the trauma whose function is to limit the pain and distress during the event. Encoded and stored peritraumatic dissociation may be retrieved during the trauma sequel and generate automatic dissociative responses.

Ruminations and worrisome thinking are characterized by a negative repetitive verbal/semantic thinking that includes both avoidant functions (e.g., Barlow, 2002; Watkins, 2008) and dysfunctional meanings. One faulty predictive function is the prevention of imagined catastrophes. Ruminative and worrisome thinking can be modeled by others and stored as dysfunctional behavioral response and/or appraisal memories.

Unorganized trauma memories may be due to (a) fragmentary retrieval of trauma-related respondent-functional-appraisal memories, (b) the retrieval of dysfunctional behavioral response memories that blocks the access to most other respondentfunctional-appraisal memory elements, and (c) a lack of inhibition of trauma-related respondent-functional-appraisal memories by functional/ incompatible respondent-functional-appraisal memories.

Since the retrieval of dysfunctional appraisal memories may be accompanied by the retrieval of respondent-functional memory elements, negative thoughts may be experienced as "emotional" and "real". This may explain the automaticity and strong emotions associated with some negative thoughts.

The inhibition of incompatible respondent-functional-appraisal memories by trauma-related respondent-functional-appraisal memories enables retrieval triggers to automatically retrieve dysfunctional respondent-functional-appraisal memory elements. Thus, retrieved trauma-related respondent-functionalappraisal memories may be experienced as occurring in the present rather than as a past event since there is no temporary access to incompatible respondent-functional-appraisal memories.

Anniversary reactions can be explained as anniversary dates, occasions and events that function as unique retrieval triggers of dysfunctional respondent-functional-appraisal memories.

Other psychopathology disorders may be conceptualized in the same manner as PTSD in terms of the behavioral-cognitive inhibition theory (e.g., see Tables 1 and 2).

\section{Respondent-Functional-Appraisal Memory Associative Networks}

Respondent-functional-appraisal memory associative networks consist of multiple respondent-functional- appraisal memories that are associated with each other and that may more or less mutually inhibit or reinforce each other (see Figure 2). A dysfunctional respondent-functional-appraisal memory associative network is characterized by the following:

- Associations between different dysfunctional respondent- 


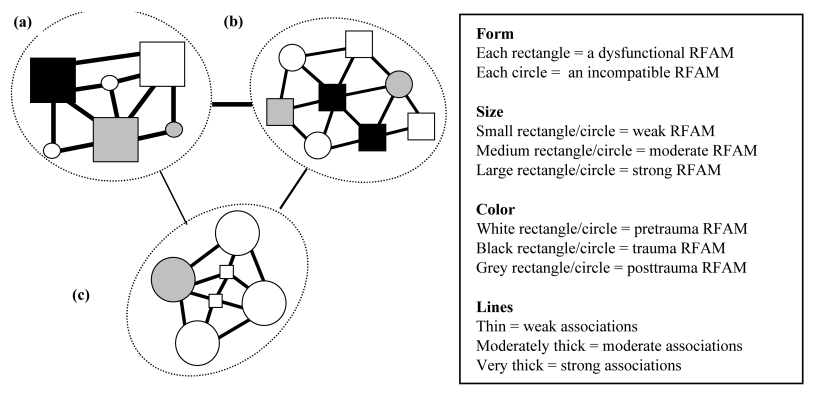

Figure 2.

Illustration of (a) a very dysfunctional respondent-functional-appraisal memory associative network (RFAM-AN) in which extremely strong dysfunctional respondent-functional-appraisal memories (RFAMs) have inhibited incompatible RFAMs so that the latter have become very weak, (b) a moderately dysfunctional RFAM-AN in which moderately dysfunctional RFAMs have inhibited incompatible RFAMs so that the latter have become moderately weak (and/or vice versa), and (c) a very strong incompatible RFAM-AN consisting of very strong incompatible RFAMs that have inhibited dysfunctional RFAMs so that the latter have become very weak.

functional-appraisal memories are more or less strong.

- Associations between dysfunctional respondent-functionalappraisal memories may be stronger than associations between incompatible respondent-functional-appraisal memories

- Dysfunctional respondent-functional-appraisal memory associative networks contain excessively inhibited incompatible respondent-functional-appraisal memories.

If dysfunctional respondent-functional-appraisal memories are strongly interconnected, the retrieval of one type of dysfunctional memory should lead to the retrieval of other dysfunctional memories. If correct, such associations may explain why a successful treatment of one axis-1 disorder may lead to an automatic improvement in comorbid axis-1 disorders. If associations between different dysfunctional respondent-functional-appraisal memories are weak, retrieval of one memory will less likely lead to the retrieval of other memories, or to an automatic improvement of disorders that have not been targeted in treatment. Strong associations between dysfunctional respondent-functional-appraisal memories should lead to an easy and automatic retrieval of multiple memories, especially if associations between incompatible respondent-functional-appraisal memories are weak.

Dysfunctional respondent-functional-appraisal memories may inhibit or reinforce each other. Depressive-related respondentfunctional-appraisal memories may reinforce other depressiverelated respondent-functional-appraisal memories. Fear-related respondent-functional-appraisal memories may reinforce other fear-related respondent-functional-appraisal memories. It may be an interesting question whether depressive-related respondent-functional-appraisal memories may temporarily inhibit anxiety-related respondent-functional-appraisal memories (e.g., Mogg, Bradley, Williams, \& Mathews, 1993). If so, when depressive-related respondent-functional-appraisal memories become inhibited anxiety-related respondent-functional-appraisal memories may become more easily accessible for retrieval.

Dysfunctional respondent-functional-appraisal memories may overlap in certain characteristics with incompatible/functional respondent-functional-appraisal memories. For example, encoded and stored salient physical characteristics of a perpetrator may be similar to physical characteristics of a significant per- son. Memories or currently encoded aspects of such a significant other may be a retrieval trigger for memories of a perpetrator and a traumatic event. Another example is that for rape victims with chronic PTSD sexual activities with a partner may function as a retrieval trigger of distressing rape trauma memories.

Dysfunctional respondent-functional-appraisal memories in complex PTSD may contain complex memories of (a) sexual and physical abuse committed by a parent or caretaker, (b) the need for love and dependence from the same person, and (c) an excessive deprivation in essential emotional, social and other important human needs (Kohlenberg et al., 2006).

Respondent-functional-appraisal memories in PTSD as a result of type 1 vs. type 2 traumatic events (Terr, 1991) may differ considerably. In PTSD as a result of type 1 traumas dysfunctional respondent-functional-appraisal memory associative networks may more likely be characterized by moderately dysfunctional and moderately inhibited incompatible/ functional respondent-functional-appraisal memories (see upper right part of figure 2). In PTSD as a result of type 2 traumas dysfunctional respondent-functional-appraisal memory associative networks may more likely to be characterized by extremely dysfunctional respondent-functional-appraisal memories and excessively inhibited incompatible respondent-functional-appraisal memories (see upper left part of Figure 2).

Retrieved dysfunctional respondent-functional- appraisal memories vary in the amount of distress they elicit. Primary memories ought most usually to elicit the most distressing symptoms, be more non-conscious and be more difficult to deliberately retrieve than secondary respondent-functional-appraisal memories. Secondary memories ought to be more verbally accessible and easy to deliberately retrieve.

\section{Therapeutic Inhibition}

Various types of incompatible respondent-functional- appraisal memories, behaviors and appraisals are illustrated in table 3. A more extensive focus is made on imagery-related incompatible respondent-functional-appraisal memories that constitute (1) encoded and stored life events incompatible to the trauma in several problem areas and/or central themes, and (2) modified trauma-related imagery by rescripting techniques on the basis of increased self-efficacy and nurturing. Other types of incompatible respondent-functional-appraisal memories are more summarily presented in table 3 . Incompatible respondent-functional-appraisal memory elements may be retrieved in order to (a) inhibit dysfunctional respondent-functional-appraisal memories, (b) motivate functional behavioral coping, and/or (c) instigate more functional appraisals. Functional behavioral coping and functional re-appraisals in response to retrieval triggers of dysfunctional respondent-functional-appraisal memories may lead to the development of incompatible respondent-functional- appraisal memories.

A distinction is made between within respondent-functionalappraisal memory inhibition and between respondent-functional-appraisal memory inhibition. In within respondent-functional-appraisal memory inhibition incompatible memory elements within respondent-functional-appraisal memories are developed through the encoding and storing of: (a) incompatible/functional behaviors and consequences in relation to the negative predictions that are made during dysfunctional 


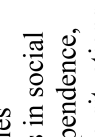

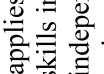

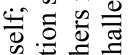

要

:

o: औै

․․

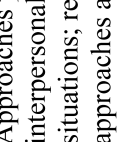

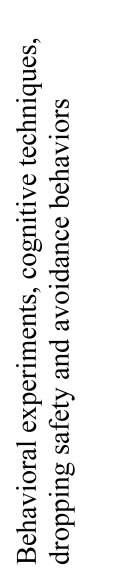

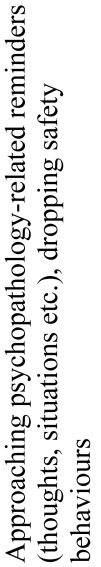

造

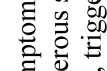

है है

章

造完

荡

论 离

苋苛.

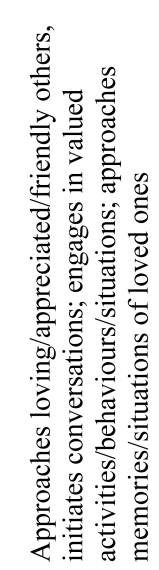

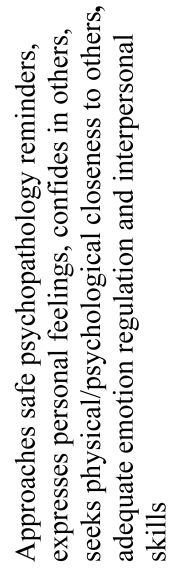

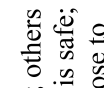
훈

는

.

心

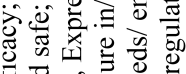

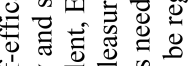

跑

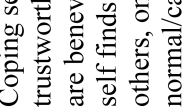

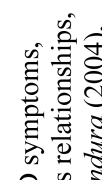

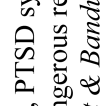

政高

言 今心

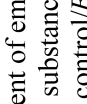

豆

密察

政密

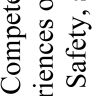

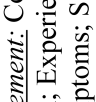

을

s

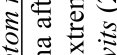

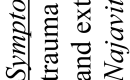

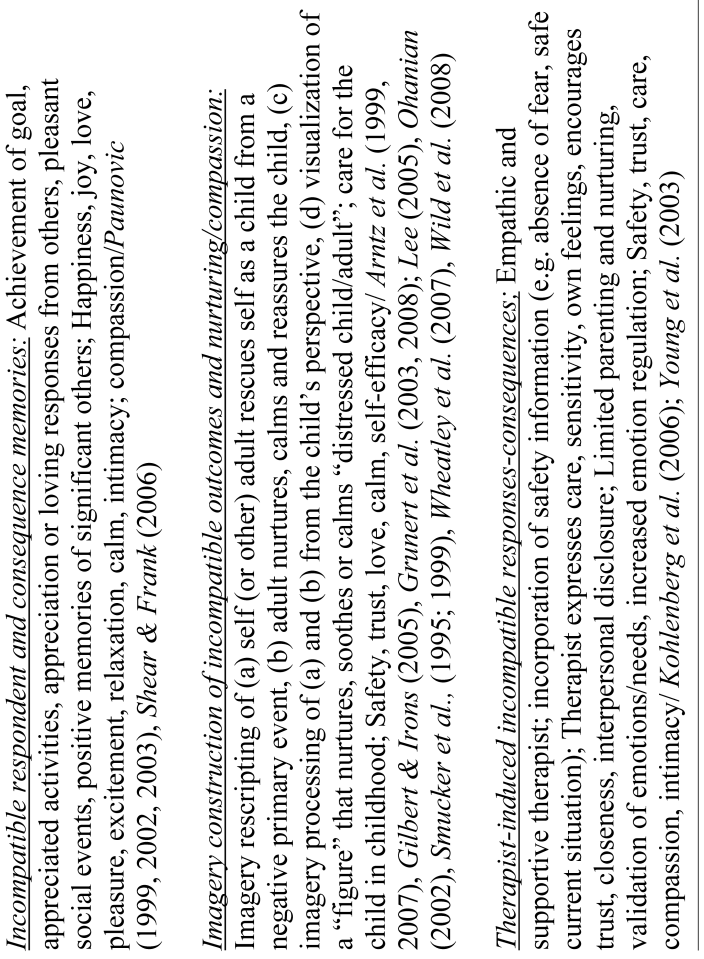


respondent-functional-appraisal memory retrieval, (b) the absence of excessively distressing emotional, physiological and pain responses during the retrieval of dysfunctional respondent-functional- appraisal memory elements, and (c) realistic re-appraisals of current contingencies and retrieved psychopathology-related respondent-functional-appraisal memories.

In between respondent-functional-appraisal memory inhibittion incompatible respondent-functional- appraisal memories that map onto central problem areas of dysfunctional respondent-functional-appraisal memories are utilized as inhibitors to the latter. In PTSD respondent-functional-appraisal memories that are associated with a high degree of safety, trust, intimacy, control and self-worth are incompatible to the high degree of danger, lack of trust and intimacy, low control and low selfworth that are found in this disorder (see Resick \& Schnicke, 1993 for these problem areas). Between respondent-functionalappraisal memory inhibition can be accomplished by retrieving primary respondent-functional-appraisal memories of safety, trust, intimacy, control and self-worth in the same circumstances as dysfunctional respondent-functional-appraisal memories are retrieved. In addition, behavioral activation in relevant problem areas may lead to the encoding and storing of new relevant respondent-functional-appraisal memories. Another conceptualization of relevant problem areas includes respondent-functional-appraisal memories of activities and/or events associated with pleasure, nurturing and mastery. Pleasure and nurturing are incompatible to numbing, depressive symptoms and a lack of self-worth. Mastery (e.g., Benight \& Bandura, 2004) is incompatible to a lack of control and helplessness often found in traumatized individuals and other psychopathology disorders. Paunović $(1999,2002,2003)$ illustrates in several case studies how incompatible respondent and consequence memories can be utilized in order to counter numbing symptoms in PTSD and inhibit primary trauma-related respondent memories. Furthermore, behavioral activation in life areas that may provide pleasure, nurturing and self-efficacy can be encoded and stored as incompatible respondent-functional-appraisal memories. Such memories may in turn be utilized or function as effective inhibitors to dysfunctional respondentfunctional-appraisal memories.

Recovery from psychopathology symptoms may require the fulfillment of the following conditions: (a) the retrieval of dysfunctional respondent-functional-appraisal memories, (b) the retrieval of incompatible respondent-functional-appraisal memories and/or (c) the encoding and storing of incompatible current stimuli, responses and appraisals in the same circumstances as retrieved dysfunctional respondent-functional-appraisal memories. The encoded and stored incompatible stimuli, responses and appraisals become incorporated into the dysfunctional respondent-functional-appraisal memory. If the incompatible memory elements are strong enough they may be able to inhibit the dysfunctional memory elements. Optimal inhibition may not be achieved if (a) dysfunctional respondent-functionalappraisal memories are incompletely retrieved, (b) incompatible respondent-functional-appraisal memories are not strong enough, (c) incompatible respondent-functional-appraisal memories don't map onto all relevant problem areas, and/or (d) incompatible current contingencies and associated behaviors and appraisals are not properly encoded and stored.

Recovery from comorbid psychopathology may occur under the following conditions: (a) retrieval of the dysfunctional respondent-functional-appraisal memory network, (b) retrieval of the dysfunctional network in the same circumstances as when incompatible respondent-functional-appraisal memory networks are retrieved, or current incompatible contingencies (e.g., functional behaviors, appraisals etc.) that map onto dysfunctional respondent-functional-appraisal memory networks are encoded, stored and incorporated into the dysfunctional memory network.

One may hypothesize at least four possible end-point outcomes of attempted therapeutic inhibition. First, complete inhibition which constitutes an optimal and generalized inhibition to all primary dysfunctional respondent-functional-appraisal memories. Second, chronic dysfunctional respondent-functionalappraisal memory retrieval where therapeutic inhibition has not been accomplished, dysfunctional respondent-functional-appraisal memories are constantly retrieved and generate severe psychopathology symptoms. Third, an excessive avoidance of dysfunctional respondent-functional-appraisal memory retrieval. Here the encoding of retrieval triggers is excessively avoided, and a retrieval of dysfunctional respondent-functionalappraisal memories leads to an immediate and automatic shutdown of dysfunctional memory elements. Fourth, excessively negative current appraisals may continuously reinforce dysfunctional respondent-functional-appraisal memories.

\section{Discussion}

Examples of testable hypotheses that can be deduced from the model are the following. First, dysfunctional respondentfunctional-appraisal memory elements may be measured by instruments that tap onto faulty/functional appraisals and predictions, distressing vs. incompatible respondent and operant responses, reinforcing and punishing consequences and dysfunctional vs. functional contingencies. Groups that fulfill criteria for various types of disorders should be compared to groups without the respective disorder on corresponding measures. In PTSD a group that have been traumatized but don't fulfill the criteria for PTSD should also be included in order to determine the impact of the event per see. Second, the inhibittion of dysfunctional respondent-functional-appraisal memories can be accomplished through various routes of inhibition: (a) the inhibition of dysfunctional respondent memories by incompatible respondent memories, (b) the inhibition of faulty appraisal memories by realistic appraisal memories, (c) the inhibition of dysfunctional behavioral response memories by functional behavioral response memories (d) the inhibition of faulty discriminative memories by realistic discriminative memories, (e) the inhibition of dysfunctional punishing/reinforcing consequence memories by functional/incompatible consequence memories, (f) the inhibition of dysfunctional respondent-functional-appraisal memories through the route of currently encoded and stored incompatible current contingencies, and (g) the inhibition of one type of dysfunctional respondent-functional-appraisal memory element by another type of incompatible respondent-functional-appraisal memory element. Measures that tap various types of respondent-functional-appraisal memory elements should be administered before and after a treatment and at follow-up in order to assess the degree of inhibition. In addition, it may be important to administer key measures 
during a treatment at various points in time in order to determine when the inhibition takes place and how the improvement curve looks like through time. In a treatment group measures that tap onto dysfunctional respondent-functional-appraisal memory elements should diminish significantly from pre to posttreatment as well as measures that tap onto psychopathology symptoms. In a randomly assigned wait control condition such improvements should not occur. Third, the more dysfunctional respondent-functional-appraisal memory elements are, the more likely they are to influence current psychopathology symptoms, appraisals and behaviors. A psychopathology group with significantly more dysfunctional respondent-functional-appraisal memory elements should display significantly more psychopathology symptoms and ought to be more difficult to treat. The latter may be indexed by the need for more sessions in order to achieve a successful treatment outcome and less improvement in therapy. In addition, there might be a need for a broader treatment strategy that focus on all the treatment needs (e.g., on all dysfunctional respondent-functional-appraisal memory elements). Fourth, the more distressing and serious life events an individual has experienced, the more likely it may be that dysfunctional respondent-functional-appraisal memories may developed. The seriousness of distressing life events may be measured by developing measures that tap onto the degree of exposure to various types of distressing life events. In PTSD such measures have been developed. However, to the best of the author's knowledge such measures don't exist in other psychopathology disorders. In addition, measures that tap onto psychological vulnerabilities may be utilized. Corresponding measures can be developed in order to tap various degrees and amounts of incompatible or functional life events, as well as degrees of emotional engagement into such encoded and stored experiences. Such experiences in interaction with an individual's responses to such events may function as protective factors if highly functional or incompatible respondent-functional-appraisal memories have been developed.

Evidence-based cognitive-behavioral therapies may primarily exert their efficacy through different routes of inhibition. In in vivo, imaginal and interoceptive exposure incompatible respondent-functional-appraisal memories may mainly develop through (a) the encoding and storing of diminished physiological/emotional reactions during exposure, (b) the encoding and storing of the absence of imagined negative consequences during exposure, and (c) the retrieval of functional/incompatible respondent-functional-appraisal memory elements. In cognitive therapy the primary aim may be to inhibit faulty appraisal memories by developing new functional/incompatible respondent-functional-appraisal memories. When faulty primary appraisal memories and other dysfunctional respondent-functional-appraisal memories are retrieved central re-appraisals may occur due to (a) the encoding and storing of incompatible current contingencies, and (b) the retrieval of incompatible respondent-functional-appraisal memory elements. Current realistic current contingencies and functional appraisals become encoded and stored in memory, and these memories may start to function as incompatible respondent-functional-appraisal memory elements. In imagery rescripting a primary aim is to rescript two types of outcomes in memories of primary negative events: (a) from non-controllable distressing events to a mastery of the negative situations, and (b) from post-event sequels during which there was a lack of social support or nurturing to the nurturing of the self.

Young's schema therapy model for personality disorders (Young et al., 2003) is re-conceptualized in accordance with the behavioral-cognitive inhibition theory. Primarily, schemas from Youngs model are behaviorally formulated (see Table 2). One important question might be how to categorize the various types of encoded and stored events, related emotional responses and other memory elements in terms of various degrees of intensity, frequency and durability. Young's maladaptive coping responses are conceptualized as dysfunctional behavioral responses to retrieval triggers and retrieved respondent-functional-appraisal memories.

Brewin (2006) contrasts the accommodation model to the activation-deactivation model. According to the accommodation model therapy modifies structures in memory that give rise to negative beliefs (e.g., Beck et al., 1985; Foa et al., 1989). On the contrary, the activation-deactivation model (Brewin, 2006) assumes that effective therapy is due to the deactivation or blocking of negative memories and the activation and creation of positive memories. The key element of effective CBT is that positive memories should win the retrieval competition over negative memories. The behavioral-cognitive inhibition theory is compatible with both of these models. First, dysfunctional respondent-functional-appraisal memories must be retrieved. Second, dysfunctional respondent-functional-appraisal memories must be inhibited by incompatible or functional respondent-functional-appraisal memories or encoded and stored current contingencies. Functional inhibition is accomplished when the retrieval of incompatible respondent-functional-appraisal memories take precedence over psychopathology-related retrieved respondent-functional-appraisal memories. Ideally, incompatible respondent-functional-appraisal memories should dominate over dysfunctional respondent-functional-appraisal memories. This is in line with the activation-deactivation model. This in turn must be associated with a change of the respondent-functional-appraisal memory network structure that is in accordance with the accommodation model.

In the behavioral-cognitive inhibition theory appraisals are conceptualized both in terms of (a) appraisal memories somewhat similar to the "meaning representations" in the emotional processing theory (e.g. Foa \& Kozak, 1986; Foa \& Rothbaum, 1998; Foa, Steketee, \& Rothbaum, 1989), and (b) as current appraisals as in Ehlers and Clarks cognitive theory of PTSD (Ehlers \& Clark, 2000). In addition, the behavioral-cognitive inhibition theory conceptualizes respondent and operant mechanisms both in terms of dysfunctional memories and current contingencies that bi-directionally influence each other.

The "nature of" dysfunctional vs. incompatible respondentfunctional-appraisal memories and memory networks presented in Figure 2 have been made primarily for illustrational purposes. The "exact nature of" respondent-functional-appraisal memories and memory networks in various types of psychopathology disorders is an empirical question. In addition, the two-dimensionality of the presented figure may not optimally illustrate the interdependence between various types of respondent-functional-appraisal memory elements and memories.

Primary dysfunctional respondent-functional-appraisal memory elements may become more or less permanently modified due to the encoding and storing of similar postevent stimuli and 
responses that to a certain degree don't match the originally encoded and stored features. Original memories of real life events can be distorted by post-event stimuli such as faulty police investigatory procedures that may create new features into the original memories (Loftus, 2003). Distorted memories may still elicit the same or similar psychopathology symptoms that may need to be treated.

Some emotions presented in Table 2 (e.g., emotions labeled as "loneliness" and "abandonment") may constitute questionable concepts of emotions. They may not match conceptualizations of primary (innate) or common secondary emotions (appraisal-driven). However, such concepts may be adequate in order to tap some emotional responses to certain types of distressing life events.

Some individuals may have few existing incompatible or functional respondent-functional-appraisal memories due to long-lasting life experiences of deprivation and punishments. Such individuals may be particularly prone to develop personality disorders. In such cases longer-term therapy is needed that focuses on providing incompatible experiences that at least partially fulfils arrested needs and counters the effects of punishments. Over time, strong enough incompatible respondentfunctional-appraisal memories may be developed that are capable to inhibit dysfunctional respondent-functional-appraisal memories

One potentially interesting question is whether different types of respondent-functional-appraisal memories can be categorized into various types of psychological vulnerabilities. Not necessarily in accordance with a dichotomous categorization of generalized vs specific psychological vulnerabilities (e.g., Barlow, 2002). Another important question is what types of psychological vulnerabilities, and/or constellations of such vulnerabilities, may lead to the development of specific types of or combinations of psychopathology disorders. A third potentially important question is how to conceptualize biological vulnerability.

To summarize, the main strengths of the behavioral-cognitive inhibition theory is that (a) it comprehensively accounts for comorbidity, numbing symptoms and other PTSD-related symptomatology, (b) it may be able to explain the development and maintenance of both single psychopathology disorders as well as a broad range of psychopathology disorders, (c) it is parsimonious in relation to its broad applicability, and (d) it solves the overdetermination problem.

\section{References}

Amdur, R. L., Larsen, R., \& Liberzon, I. (2000). Emotional processing in combat-related posttraumatic stress disorder: A comparison with traumatized and normal controls. Journal of Anxiety Disorders, 14, 219-238.

American Psychiatric Association. (1994). Diagnostic and Statistical Manual of Mental Disorders, $4^{\text {th }}$ edition. Washington, DC: Author.

Arntz, A., Tiesema, M., \& Kindt, M. (2007). Treatment of PTSD: A comparison of imaginal exposure with and without imagery rescripting. Journal of Behavior Therapy and Experimental Psychiatry, 38, 345-370.

Arntz, A. \& Weertman, A. (1999). Treatment of childhood memories: Theory and practice. Behaviour Research and Therapy, 37, 715-740.

Baldwin, J. D. \& Baldwin, J. I. (2001). Behavior principles in everyday life, 4th edition. New Jersey: Prentice Hall.

Barlow, D. H. (2002). Anxiety and its disorders. New York: Guilford
Press.

Barrett, P. M., Rapee, R. M., Dadds, M. M., \& Ryan, S. M. (1996). Family enhancement of cognitive style in anxious and aggressive children. Journal of Abnormal Child Psychology, 24, 187-203.

Beck, A. T., Emery, G., \& Greenberg, R. L. (1985). Anxiety disorders and phobias: A cognitive perspective. New York: Basic Books.

Beck, A. T., Rush, A. J., Shaw B. F., \& Emery, G. (1979). Cognitive therapy of depression. New York: Guilford Press.

Benight, C. \& Bandura, A. (2004). Social cognitive theory of posttraumatic recovery: The role of perceived self-efficacy. Behaviour Research and Therapy, 42, 1129-1148.

Brewin, C. (2006). Understanding cognitive behaviour therapy: A retrieval competition account. Behaviour Research and Therapy, 44, 765-784.

Brewin, C. R., Dalgleish, T, \& Joseph, S. (1996). A dual representation theory of posttraumatic stress disorder. Psychology Review, 103, 670-686.

Brewin, C. R., Watson, M., McCarthy, S., Hyman, P., \& Dayson, D. (1998). Intrusive memories and depression in cancer patients. Behaviour Research and Therapy, 36, 1131-1142.

Chorpita, B. F. \& Barlow, D. H. (1998). The development of anxiety: The role of control in the early environment. Psychological Bulletin 124, 3-21

Clark, D. M. (1999). Anxiety disorders: why they persist and how to treat them. Behaviour Research and Therapy, 37, 5-27.

Cloitre, M., Cohen, L. R. \& Koenen, K. C. (2006). Treating survivors of childhood abuse: Psychotherapy for the interrupted life. New York: Guilford Press.

Cloitre, M., Cohen, L.R., \& Scarvalone, P. (2002). Understanding revictimization among childhood sexual abuse survivors: An interpersonal schema approach. Journal of Cognitive Psychotherapy: An International Quarterly, 16, 91-111.

Cloitre, M. \& Rosenberg, A. (2006). Sexual revictimization. In V.M. Follette and J.I. Ruzek (Eds.), Cognitive-behavioral therapies for trauma (pp. 321-361). New York: Guilford Press.

Cohen, J. A., Mannarino, A. P., \& Deblinger, E. (2006). Treating trauma and traumatic grief in children and adolescents. New York: Guilford Press.

Dalgleish, T. (2004). Cognitive theories of posttraumatic stress disorder: The evolution of multi-representational theorizing. Psychological Bulletin, 130, 228-260.

Davey, G. C. L. An expectancy model of laboratory preparedness effects. Journal of Experimental Psychology: General, 121, 24-40.

Day, S., Holmes, E. A., \& Hackman, A. (2004). Occurrence of imagery and its link with early memories in agoraphobia. Memory, 12, 416-427.

Ehlers, A. (1993). Somatic symptoms and panic attacks: A retrospective study of learning experiences. Behaviour Research and Therapy, $31,269-278$

Ehlers, A. \& Clark, D.M. (2000). A cognitive model of posttraumatic stress disorder. Behaviour Research and Therapy, 38, 319-345.

Ehlers, A., Clark, D. M., Dunmore, E., Jaycox, L., Meadows, E., \& Foa, E. B. (1998). Predicting response to exposure treatment in PTSD: The role of mental defeat and alienation. Journal of Traumatic Stress, $11,457-471$

Ehlers, A., Hackmann, A., \& Michael, T. (2004). Intrusive re-experiencing in posttraumatic stress disorder: Phenomenology, theory and therapy. Memory, 12, 403-415.

Ehlers, A., Hackmann, A., Steil, R., Clohessy, S., Wenninger, K., \& Winter, H. (2002). The nature of intrusive memories after trauma: The warning signal hypothesis. Behaviour Research and Therapy, 40, 995-1002

Ehlers, A., Mayou, R. A., \& Bryant, B. (1998). Psychological predictors of chronic PTSD after motor vehicle accidents. Journal of $A b-$ normal Psychology, 107, 508-519.

Engelhard, I. M., van den Hout, M. A., Arntz, A., \& McNally, R. J. (2002). A longitudinal study of "intrusion-based reasoning" and posttraumatic stress disorder after exposure to a train disaster. Behaviour Research and Therapy, 40, 1415-1424. 
Foa, E. B. \& Kozak, M. J. (1986). Emotional processing of fear: exposure to corrective information. Psychological Bulletin, 99, 20-35.

Foa, E. B., Riggs, D. S., \& Gershuny, B. S. (1995). Arousal, numbing, and intrusion: Symptom structure of PTSD following assault. American Journal of Psychiatry, 152, 116-120.

Foa, E. B. \& Rothbaum, B.O. (1998). Treating the trauma of rape: Cognitive behavioral therapy for PTSD. New York: Guilford Press.

Foa, E. B., Steketee, G, \& Rothbaum, B. O. (1989). Behavioral-cognitive conceptualizations of post-traumatic stress disorder. Behavior Therapy, 20, 155-176.

Follette, W. C. \& Naugle, A. E. (2006). Functional analytic clinical assessment in trauma treatment. In V.M. Follette and J.I. Ruzek (Eds.), Cognitive-behavioral therapies for trauma (pp. 17-33). New York: Guilford Press.

Gilbert, P. \& Irons, C. (2005). Compassionate mind training, for shame and self-attacking, using cognitive, behavioral, emotional and imagery interventions. In P. Gilbert (Ed.), Compassion: Conceptualizations, research, and use in psychotherapy (pp. 263-325). London: Brunner-Routledge.

Grunert, B. K., Smucker, M. R., Weis, J. M., \& Rusch, M. D. (2003). When prolonged exposure fails: Adding an imagery-based cognitive restructuring component in the treatment of industrial accident victims suffering from PTSD. Cognitive and Behavioral Practice, 10, 333-346.

Grunert, B. K., Weis, J. M., Smucker, M. R., \& Christianson, H. F. (2007). Imagery rescripting and reprocessing therapy after failed prolonged exposure for post-traumatic stress disorder following industrial injury. Journal of Behavior Therapy and Experimental Psychiatry, 38, 317-328.

Hackmann, A., Clark, D. M., \& McManus, F. (2000). Recurrent images and early memories in social phobia. Behaviour Research and Therapy, 38, 601-610.

Hackmann, A. \& Holmes, E. A. (2004). Reflecting on imagery: A clinical perspective and overview of the special issue of memory on mental imagery and memory in psychopathology. Memory, 12, $389-402$.

Hackmann, A., Surawy, C., \& Clark, D. M. (1998). Seeing yourself through others eyes: A study of spontaneously occurring images in social phobia. Behavioural and Cognitive Psychotherapy, 26, 3-12.

Holmes, E. A., Arntz, A., \& Smucker, M. R. (2007). Imagery rescripting in cognitive behavior therapy: Images, treatment techniques and outcomes. Journal of Behavior Therapy and Experimental Psychiatry, 38, 297-305.

Holmes, E. A., Grey, N., \& Young, K.A.D. (2005). Intrusive images and "hotspots" of trauma memories in posttraumatic stress disorder: An exploratory investigation of emotions and cognitive themes. Journal of Behavior Therapy and Experimental Psychiatry, 36, 3-17.

Hoover, C. F. \& Insel, T. R. (1984). Families of origin in obsessive-compulsive disorder. Journal of Nervous and Mental Disease, 172, 207-215.

Hunt, M., Bylsma, L., Brock, J., Fenton, M., Goldberg, A., Miller, R., Tran, T., \& Urgelles, J. (2006). The role of imagery in the maintenance and treatment of snake fear. Journal of Behavior Therapy and Experimental Psychiatry, 37, 283-298.

Keane, T. M., Zimering, R. T., \& Caddell, J. M. (1985). A behavioral formulation of posttraumatic stress disorder. Behavior Therapist, 8 , 9-12.

Kohlenberg, B. S., Tsai, M., \& Kohlenberg, R. J. (2006). Functional analytic psychotherapy and the treatment of complex posttraumatic stress disorder. In V.M. Follette and J.I. Ruzek (Eds.), Cognitive-behavioral therapies for trauma (pp. 173-197). New York: Guilford Press.

Kubany, E. S. \& Manke, F. P. (1995). Cognitive therapy for trauma-related guilt: Conceptual bases and treatment outlines. Cognitive and Behavioral Practice, 2, 27-61.

Kubany, E. S. \& Ralston, T. C. (2006). Cognitive therapy for trauma-related guilt and shame. In V.M. Follette and J.I. Ruzek (Eds.), Cognitive-behavioral therapies for trauma (pp. 258-289). New York: Guilford Press.
Kuyken, W. \& Brewin, C. R. (1995). Autobiographical memory functioning in depression and reports of early abuse. Journal of Abnormal Psychology, 104, 585-591.

Laor, N., Wolver, L., Mayes, L. C., Gershon, A., Weizman, R., \& Cohen, D. J. (1997). Israeli pre-school children under Scuds: A 30-month follow-up. Journal of American Academy of Child and Adolescent Psychiatry, 36, 349-356.

Last, C. G., Barlow, D. H., \& O’Brien, G. T. (1984). Precipitants of agoraphobia: Role of stressful life events. Psychological Reports, 54, 567-570.

Lazarus, R. S. \& Folkman, S. (1984). Stress, appraisal, and coping. New York: Springer Publishing Company.

Lee, D. A. (2005). The perfect nurturer: A model to develop a compassionate mind within the context of cognitive therapy. In P. Gilbert (Ed.), Compassion: Conceptualizations, research, and use in psychotherapy (pp. 326-351). London: Brunner-Routledge.

Lewinsohn, P. M., Hoberman, H. M., Teri, L., \& Hautzinger, M. (1985). An integrative theory of depression. In S. Reiss and R.R. Bootzin (Eds.), Theoretical issues in behavior therapy (pp. 331-359). Orlando, FL: Academic Press.

Lieberman, A. F. \& Amaya-Jackson, L. (2005). Reciprocal influences of attachment and trauma: Using a dual lens in the assessment and treatment in infants, toddlers, and preschoolers. In L. Berlin, Y. Ziv, L. Amaya-Jackson and M.T. Greenberg (Eds.), Enhancing early attachments: Theory, research, intervention, and policy, pp. 120-126. New York: Guilford Press.

Litz, B. T. (1992). Emotional numbing in combat-related post-traumatic stress disorder: A critical review and reformulation. Clinical Psychology Review, 12, 417-432.

Litz, B. T., Orsillo, S. M., Kaloupek, D. \& Weathers, F. (2000). Emotional processing in posttraumatic stress disorder. Journal of Abnormal Psychology, 109, 26-39.

Loftus, E. F. (2003). Our changeable memories: Legal and practical implications. Nature Reviews: Neuroscience, 4, 231-234.

Martell, C. R., Addis, M. E., \& Jacobson, N. S. (2001). Depression in context: Strategies for guided action. New York: W.W. Norton \& Company.

Martin, G. \& Pear, J. (2007). Behavior modification: What it is and how to do it. New Jersey: Prentice Hall.

Miller, M. W. \& Litz, B. T. (2004). Emotional-processing in posttraumatic stress disorder II: Startle reflex modulation during picture processing. Journal of Abnormal Psychology, 113, 451-463.

Mogg, K., Bradley, B. P., Williams, R., \& Mathews, A. M. (1993). Subliminal processing of emotional information in anxiety and depression. Journal of Abnormal Psychology, 102, 304-311.

Mueser, K. T., Rosenberg, S. D., \& Rosenberg, H. J. (2009). Treatment of posttraumatic stress disorder in special populations: A cognitive restructuring program. Washington, DC: American Psychological Association.

Najavits, L. M. (2001). Seeking safety: A treatment manual for PTSD and substance abuse. New York: Guilford Press.

Nolen-Hoeksema, S., Girgus, J. S., \& Seligman, M. E. (1992). Predictors and consequences of childhood depressive symptoms: A 5-year longitudinal study. Journal of Abnormal Psychology, 101, 405-422.

Ohanian, V. (2002). Imagery rescripting within cognitive behavior therapy for bulimia nervosa: An illustrative case report. International Journal of Eating Disorders, 31, 352-357.

Osman, S., Cooper, M., Hackmann, A., \& Veale, D. (2004). Spontaneously occurring images and early memories in people with body dysmorphic disorder. Memory, 12, 428-436.

Ozer, E. J. \& Weiss, D. S. (2004). Who develops posttraumatic stress disorder? Current Directions in Psychological Science, 13, 169-172.

Paunovic, N. (1999). Exposure counterconditioning (EC) as a treatment for severe PTSD and depression with an illustrative case. Journal of Behavior Therapy and Experimental Psychiatry, 30, 105-117.

Paunovic, N. (2002). Prolonged exposure counterconditioning (PEC) as a treatment for chronic post-traumatic stress disorder and major depression in an adult survivor of repeated child sexual and physical abuse. Clinical Case Studies, 1, 148-169. 
Paunovic, N. (2003). Prolonged exposure counterconditioning as a treatment for chronic posttraumatic stress disorder. Journal of Anxiety Disorders, 17, 479-499.

Power, M. J. \& Dagleish, T. (1997). Cognition and emotion: From order to disorder. Hove, England: Psychology Press.

Rachman, S. J. (1976). The passing of the two-stage theory of fear and avoidance: Fresh possibilities. Behaviour Research and Therapy, 14, 125-131.

Rachman, S. J. (1977). The conditioning theory of fear acquisition: A critical examination. Behaviour Research and Therapy, 15, 375-387.

Resick, P. A. \& Schnicke, M.K. (1993). Cognitive processing therapy for rape victims: A treatment manual, Newbury Park, CA: Sage Publications.

Roemer, L., Litz, B. T., Orsillo, S. M., \& Wagner, A. W. (2001). A preliminary investigation of the role of strategic withholding of emotions in PTSD. Journal of Traumatic Stress, 14, 149-156.

Salkovskis, P. M., Shafran, R., Rachman, S., \& Freeston, M. H. (1999). Multiple pathways to inflated responsibility beliefs in obsessional problems: Possible origins and implications for therapy and research. Behaviour Therapy and Research, 37, 1055-1072.

Scheeringa, M. S. \& Zeanah, C. H. (2001). A relational perspective on PTSD in early childhood. Journal of Traumatic Stress, 14, 799-815.

Shear, K. \& Frank, E. (2006). Treatment of complicated grief: Integrating cognitive-behavioral methods with other treatment approaches. In V.M. Follette and J.I. Ruzek, Cognitive-behavioral therapies for trauma (pp. 290-320). New York: Guilford Press.

Smith, P., Perrin, S., Yule, W., \& Clark, D. M. (2009). Posttraumatic stress disorder: Cognitive therapy with children and young people. Florence: Routledge.

Smucker, M. R. \& Dancu, C. V. (1999). Cognitive-behavioral treatment for adult survivors of childhood trauma: Imagery rescripting and reprocessing. New Jersey: Jason Aronson, inc.

Smucker, M. R., Dancu, C., Foa, E. B., \& Niederee, J. L. (1995). Imagery rescripting: A new treatment for survivors of childhood sexual abuse suffering from posttraumatic stress. Journal of Cognitive Psychotherapy, 9, 3-17.

Somerville, K., Cooper, M., \& Hackmann, A. (2007). Spontaneous imagery in women with bulimia nervosa: An investigation into content, characteristics and links to childhood memories. Journal of Behavior Therapy and Experimental Psychiatry. 38, 435-446.

Spahic-Mihajlovic, A. S., Crayton, J. W., \& Neafsey, E. J. (2005). Selective numbing and hyperarousal in male and female Bosnian refugees with PTSD. Journal of Anxiety Disorders, 19, 383-402.

Speckens, A. E. M., Hackmann, A., Ehlers, A., \& Cuthbert, B. (2007). Imagery special issue: Intrusive images and memories of earlier adverse events in patients with obsessive compulsive disorder. Journal of Behavior Therapy and Experimental Psychiatry, 38, 411-422.

Taylor, S. (2006). Clinician's guide to PTSD: A cognitive-behavioral approach. New York: Guilford Press.

Tarrier, N., Sommerfield, C., \& Pilgrim, H. (1999). Relatives' expressed emotion (EE) and PTSD treatment outcome. Psychological Medicine, 29, 801-811.

Terr, L. C. (1991). Childhood traumas: an outline and overview. American Journal of Psychiatry, 148, 10-20.

Watkins, R. (2008). Depressive rumination - Investigating mechanisms to improve treatment. Workshop at the $1^{\text {st }}$ international conference of Forum Lundense: What makes therapy work? Towards a science of cognitive, emotional, and behavioural change, Lund, Sweden.

Wheatley, J., Brewin, C. R., Patel, T., Hackmann, A., Wells, A., Fisher, P., \& Myers, S. (2007). I'll believe it when I can see it": Imagery rescripting of intrusive sensory memories in depression. Journal of Behavior Therapy and Experimental Psychiatry, 38, 371-385.

Wild, J., Hackman, A., \& Clark, D. M. (2007). When the present visits the past: Updating traumatic memories in social phobia. Journal of Behavior Therapy and Experimental Psychiatry, 38, 386-401.

Wild, J., Hackmann, A., \& Clark, D. M. (2008). Rescripting early memories linked to negative images in social phobia: A pilot study. Behavior Therapy, 39, 47-56.

Wolpe, J.(1995). Reciprocal inhibition: Major agent of behavior change. In W. Donahue and L. Krasner (Eds), Theories of behavior therapy, pp. 23-57, Washington, DC: American Psychological Association.

Young, J. E., Klosko, J. S. \& Weishaar, M. E. (2003). Schema therapy: A practitioner's guide. New York: Guilford Press. 